Results: The mean TBS at the lumbar spine was $1.38 \pm 0.13$. The TBS showed a negative correlation with disease duration and inflammatory markers, and a positive correlation with BMD at the lumbar spine, femoral neck, and total hip. It also showed a negative correlation with sacroilitis grade. BMD at the lumbar spine positively correlated with SASSS, whereas TBS showed a negative correlation. A significant decrease in TBS values was observed in patients with spinal radiographic progression $(\mathrm{p}=0.001)$. Multivariate analysis showed that $\mathrm{ESR}$ and sacroilitis were independently associated with TBS $(p=0.006$ and $<0.001$, respectively). Ten patients had morphometric vertebral fractures. The mean TBS was lower in patients with vertebral fracture than in age-matched patients without fracture $(p=0.028)$.

Conclusions: The TBS in young male patients with AS is associated with the ESR and severity of sacroilitis. The TBS may be useful as a tool for assessing osteoporosis in AS.

Disclosure of Interest: None declared

DOI: 10.1136/annrheumdis-2017-eular.1254

\section{FRI0448 EVALUATION OF SUPPURATIVE HIDRADENITIS IN PATIENTS WITH CHRONIC ARTHRITIS TREATED WITH FULL AND TAPERED BIOLOGICAL DISEASE-MODIFYING ANTIRHEUMATIC DRUGS}

L. Valor, D. Hernández-Flórez, T. del Río, J.G. Ovalles B, J. Martínez Barrio, I. Janta, B. Serrano, J.C. Nieto, M. Correyero Plaza, L. Garcia Montoya, C. González, F.J. López-Longo, I. Monteagudo. Hospital General Universitario Gregorio Marañón, Madrid, Spain

Background: Suppurative Hidradenitis (SH) is an inflammatory skin disease which often responds poorly to treatment. It is a disorder of the apocrine glands (axillary, inguinal and anogenital regions) that can result in infection, inflamed nodules, cysts, abscesses and sinus tracts. There is a $1-4 \%$ incidence of $\mathrm{SH}$ in patients with spondyloarthropathies and inflammatory bowel disease, possibly due to innate immune system deregulation. The use of biological disease-modifying antirheumatic drugs (bDMARD), specifically tumor necrosis factor inhibitors, has been useful in cases when other therapies fail.

Objectives: To evaluate the prevalence of $\mathrm{SH}$ using the $\mathrm{SH}$-questionnaire in bDMARD-treated chronic arthritis patients.

Methods: This cross-sectional study included 325 patients diagnosed with chronic arthritis. Patients were recruited consecutively from the Biological Therapy Unit of the Hospital General Universitario Gregorio Marañón and evaluated from January to March of 2015. All patients had been undergoing full or tapered bDMARD treatment for at least 1 year and none had any history of $\mathrm{SH}$. Those patients deemed to be in clinical remission were on tapered bDMARD dosage. All patients self-completed the validated $\mathrm{SH}$-questionnaire (1) which was considered positive when one answer was affirmative and when lesions presented in $>1$ anatomical location. Patient pathologies were subclassified into 2 groups: i) peripheral arthritis (PerAR) which includes rheumatoid arthritis (RA), psoriatic arthritis (PsA) and peripheral spondyloarthropathies (PerSpA); ii) axial spondyloarthropathies $(\mathrm{AxSpA})$. Clinical evaluation was performed by the same physician for all patients. Demographic, clinical and laboratory variables were recorded and disease status was assessed through the relevant clinical index, i.e.DAS28-ESR, DAS28-CRP, SDAI, CDAI, BASDAI, BASFI, ASDAS-CRP.

Results: SH-positive was observed in $25 / 325(7.7 \%$ vs. $92.3 \%)$ patients. Of these 25 patients, $12(48 \%)$ were female and $13(52 \%)$ male. Mean age was 52 years $(\mathrm{SD} \pm 12.9)$ and mean time since diagnosis was 14 years $(\mathrm{SD} \pm 9.3)$. Twenty-four out of 25 patients were undergoing anti-TNF treatment $(E T N=10, G O L=7, A D L=6$, $\mathrm{CTZ}=1$ ). Eighty-four per cent of patients were undergoing full bDMARD dosage with the remaining $16 \%$ on tapered. By subset pathology, $13 \mathrm{SH}$ positives were PerAR type and 12 were AxSpA (5.8\% vs. $11.8 \%, p=0.062$ ). On analysis of PerAR subtypes, we found 6 patients had PsA and 5 RA. Evaluating clinical disease activity, we found $9 / 13$ patients in the PerAR group to be in clinical remission according to DAS28-ESR and CDAI ( $p=0.02$ for both). Additionally, we found only $4 / 12$ patients in remission in the AxSpA group as defined under BASDAI, BASFI and ASDAS-CRP ( $\mathrm{p}=0.006, \mathrm{p}=0.005, \mathrm{p}=0.004$, respectively).

Conclusions: We found more SH-positives in the AxSpA than in the PerAR group, which is consistent with published data. A bDMARD tapered dosage was related to SH-positivity which might be linked to persistent and undetectable chronic inflammation.

References:

[1] Esmann S, et al. Br J Dermatol. 2010 Jul;163(1):102-6.

Disclosure of Interest: None declared

DOI: 10.1136/annrheumdis-2017-eular.4737
FRI0449 ANALYSIS OF THE CANADIAN ADALIMUMAB POST-MARKETING OBSERVATIONAL EPIDEMIOLOGICAL STUDY ASSESSING EFFECTIVENESS IN ANKYLOSING SPONDYLITIS (COMPLETEAS): ASSOCIATION BETWEEN BASELINE EXTRA ARTICULAR MANIFESTATIONS AND PATIENT-REPORTED OUTCOMES

L. Bessette ${ }^{1,2}$, B. Haraoui ${ }^{3}$, M. Khraishi ${ }^{4}$, W. Bensen ${ }^{5}$, V.P. Remple ${ }^{6,7},{ }^{1}$ Faculty of Medicine, Université Laval; ${ }^{2}$ Centre Hospitalier de l'Université Laval, Quebec; ${ }^{3}$ Centre Hospitalier de l'Université de Montréal, Montreal; ${ }^{4}$ Faculty of Medicine, Memorial University of Newfoundland, St. John's; ${ }^{5}$ Division of Rheumatology, McMaster University, Hamilton; ${ }^{6}$ School of Population and Public Health, University of British Columbia, Vancouver; ${ }^{7}$ AbbVie Corp., Montreal, Canada

Background: Ankylosing spondylitis (AS) is an immune mediated inflammatory disease. Although characterized by axial and peripheral joint manifestations, extra articular manifestations (EAMs) are a common clinical feature. EAMs have been found to negatively impact health outcomes including quality of life and work capacity.

Objectives: The aim of this analysis was to describe the prevalence of EAMs at baseline and assess their association with patient-reported outcomes (PROs) in a Canadian routine clinical care setting.

Methods: COMPLETE-AS is an ongoing observational study expected to enroll 1120 AS patients from 60-80 sites across Canada. All patients enrolled between June/2011 - October/2015 were included in this analysis. Eligible patients are antiTNF $\alpha$ naïve adults, with active AS as per the judgment of the treating physician, who require change in current AS treatment. Baseline disease parameters assessed were EAMs (collected from medical chart, physician assessment or patient report), disease activity (BASDAI) and functional status (BASFI); baseline PROs assessed were related to mental health (BDI-II), work limitations (WLQ), and quality of life (QoL; SF-36 Physical (PCS) and Mental (MCS) component summaries). Multivariate linear regression models adjusting for baseline BASDAI and BASFI assessed the impact of EAMs on PROs.

Results: A total of 569 patients were included in the current analysis. Mean (SD) age and duration of disease was $43.3(13.4)$ and 5.9 (9.8) years, respectively. The majority of patients enrolled were male $(57.1 \%)$, Caucasian $(86.1 \%)$, HLA

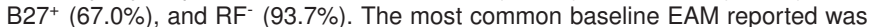
enthesitis $(15.3 \%)$, followed by psoriasis $(13.0 \%)$, inflammatory bowel disease (IBD; 9.1\%), and uveitis (3.2\%). EAM combination 1 (EAM1: all EAMs) and EAM combination 2 (EAM2: excluding psoriasis), was reported by $33.2 \%$, and $23.7 \%$ of patients, respectfully.

Regression analysis adjusting for baseline BASDAI and BASFI, found enthesitis, EAM1, and EAM2 to be significant negative predictors of SF-36 PCS scores $(p<0.05)$. Individual EMAs were not found to impact PROs, except for uveitis, found to be a negative predictor of SF-36 PCS scores for which a statistical trend was identified $(p<0.15)$. No association between EAMs and SF-36 MCS, BD-II or WLQ scores were found.

Conclusions: In a Canadian routine clinical care setting, a substantial proportion of AS patients requiring a change in treatment report EAMs. Patients with EAMs were found to have significant reduction in baseline QoL specifically related to physical functioning.

Acknowledgements: The authors wish to acknowledge JSS Medical Research, Montreal (QC) Canada for statistical analysis, medical writing and editorial assistance during the preparation of this abstract.

Disclosure of Interest: L. Bessette Consultant for: Janssen, Roche, UCB, AbbVie, Pfizer, Celgene, Lilly, Novartis, Speakers bureau: Amgen, BMS, Janssen, Roche, UCB, AbbVie, Pfizer, Merck, Celgene, Lilly, Novartis, B. Haraoui Grant/research support from: AbbVie, Amgen, BMS, Janssen, Pfizer, Roche, and UCB; Speaking engagements: Amgen, BMS, Janssen, Pfizer, and UCB, Consultant for: AbbVie, Amgen, BMS, Celgene, Eli Lilly, Janssen, Merck, Pfizer, Roche, and UCB, Speakers bureau: Amgen, BMS, Janssen, Pfizer, and UCB, M. Khraishi Consultant for: AbbVie, Speakers bureau: AbbVie, W. Bensen Consultant for: Abbvie, Amgen, BMS, Celgene, Janssen, Lilly, Novartis, Merck, Pfizer, Roche, and UCB, Speakers bureau: Abbvie, Amgen, BMS, Celgene, Janssen, Lilly, Novartis, Merck, Pfizer, Roche, and UCB, V. Remple Shareholder of: AbbVie Corp., Employee of: AbbVie Corp.

DOI: 10.1136/annrheumdis-2017-eular.3032

\section{FRI0450 COMMONALITIES AND DIFFERENCES IN DATA COLLECTION ACROSS EUROPEAN SPONDYLOARTHRITIS REGISTRIES}

M.L. Hetland ${ }^{1}$, M. Østergaard ${ }^{1}$, J. Askling ${ }^{2}$, C. Gabay ${ }^{3}$, D. Nordstrom ${ }^{4}$, ${ }^{\text {O. FitzGerald }}{ }^{5}$, M. Hernández Miguel ${ }^{6}$, M. Santos ${ }^{7}$, Z. Rotar ${ }^{8}$, H. Mann ${ }^{9}$, F. lannone ${ }^{10}$, M.J. Nissen ${ }^{3}$, E. Hauge ${ }^{1}$, J. Gomez-Reino ${ }^{11}$, F. Díaz-González ${ }^{12}$, M. Tomsic ${ }^{8}$, K. Pavelka ${ }^{9}$, F. O'Shea ${ }^{5}$, C. Sullivan ${ }^{5}$, M. van de Sande ${ }^{13}$, I.E. van der Horst-Bruinsma ${ }^{13}$, G.J. Macfarlane ${ }^{14}$, G.T. Jones ${ }^{14}$, B. Gudbjørnsson ${ }^{15}$, T.K. Kvien ${ }^{16}$ on behalf of EuroSpA Study Group. ${ }^{1}$ DANBIO, Glostrup, Denmark; ${ }^{2}$ ARTIS, Stockholm, Sweden; ${ }^{3}$ SCQM, Geneva, Switzerland; ${ }^{4}$ ROB-FIN, Helsinki, Finland; ${ }^{5}$ ASRI, Dublin, Ireland; ${ }^{6}$ Biobadaser, Barcelona, Spain; $7^{7}$ reuma.pt, Almada, Portugal; ${ }^{8}$ biorx.si, Ljubljana, Slovenia; ${ }^{9}$ ATTRA, Prague, Czech Republic; ${ }^{10}$ GISEA, Bari, Italy; ${ }^{11}$ Biobadaser, Santiago; ${ }^{12}$ Biobadaser, Santa Cruz de Tenerife, Spain; ${ }^{13} A R C$, Amsterdam, Netherlands; ${ }^{14} B s r b r-A s$, Aberdeen, UK; ${ }^{15}$ ICEBIO, Reykjavik, Iceland; ${ }^{16}$ Nordmard, Oslo, Norway

Background: High quality data from prospective, real life patients with spondy- 
loarthritis $(\mathrm{SpA})$ is needed to strengthen patient-level research in non-experimental clinical settings. A research network collaboration of registries collecting data on patients with SpA, "EuroSpA" offers opportunities to enhance research capabilities in the real world setting

Objectives: To assess patient numbers, data extent and completeness in European SpA registries and establish an international research collaboration and common data set to address key data gaps for SpA patients treated in routine clinical practice.

Methods: The "EuroSpA" research network collaboration was established between registries collecting data on SpA patients. A survey was conducted via email and follow-up interviews April-December 2016 to assess patient numbers, data availability and completeness in participating registries. Our survey tool was based on key variables identified through literature review and expert interviews. Results: 14 European rheumatology registries submitted information on their data covering approximately $63479 \mathrm{SpA}$ patients, including patients with psoriatic arthritis (PsA), ankylosing spondylitis (AS) and non-radiographic axial spondyloarthritis (nr-axSpA) (Table).

Table 1. Approximate patient numbers in each SpA registry

\begin{tabular}{lccc}
\hline Registry & \multicolumn{3}{c}{ Approximate patient numbers } \\
\cline { 2 - 4 } & PsA & AS & Nr-axSpA \\
\hline ARC (Netherlands) & 10000 & 310 & 80 \\
ARTIS (Sweden) & & 10000 & \\
ASRI (Ireland) & 800 & 630 & 150 \\
ATTRA (Czech Republic) & 500 & 2200 & 20 \\
BIOBADASER (Spain) & 350 & 500 & 650 \\
Biorx.si (Slovenia) & & 600 & 3400 \\
BSRBR-AS (Britain) & 7800 & 1500 & 600 \\
DANBIO (Denmark) & 2400 & 1200 & 120 \\
GISEA (Italy) & 376 & 343 & \\
ICEBIO (Iceland) & 1600 & 1100 & 400 \\
NOR-DMARD (Norway) & 1600 & & 2700 \\
Reuma.pt (Portugal) & 1900 & 1900 & 550 \\
ROBFIN (Finland) & 1900 & 1400 & 5970 \\
SCQM (Switzerland) & 29226 & 28283 & \\
Total & & & \\
\hline
\end{tabular}

Data coverage was comprehensive for comorbidities, demographic and treatment variables, but limited for imaging and in PsA for skin and nail manifestations (figure).

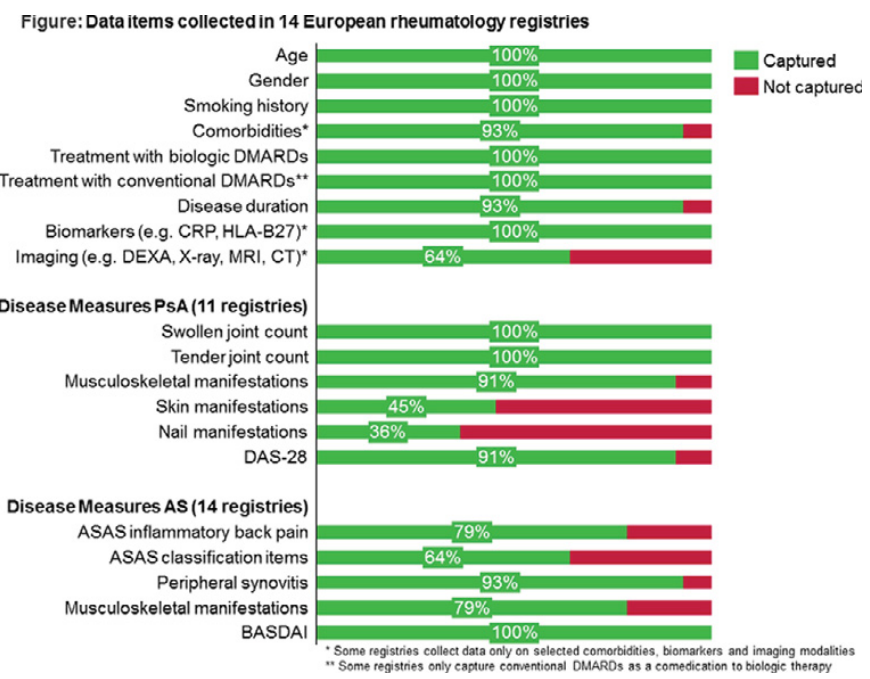

Conclusions: A European research collaboration network of SpA registries, "EuroSpA", including $\approx 63500 \mathrm{SpA}$ patients enables the collection of key patient variables and strengthens research through increased patient numbers and cross-country comparative research. While core disease activity measures for SpA patients are widely collected, an enhanced standardized core dataset could strengthen future collaboration.

Acknowledgements: The authors acknowledge Craig Richardson from Novartis Pharma AG, Carol Lines and Seline Eisenring from Quintiles IMS for support in survey data collection and editorial assistance, and Novartis Pharma AG, Basel, Switzerland for financial support of the EuroSpA initiative.

Disclosure of Interest: M. L. Hetland Grant/research support from: AbbVie, BMS, MSD, Pfizer, Orion, Novartis, Biogen, Eli Lilly, M. Østergaard Grant/research support from: Abbvie, BMS, Boehringer-Ingelheim, Celgene, Eli-Lilly, Centocor, GSK, Hospira, Janssen, Merck, Mundipharma, Novartis, Novo, Orion, Pfizer, Regeneron, Schering-Plough, Roche, Takeda, UCB, J. Askling: None declared, C. Gabay Grant/research support from: Roche, Pfizer, AB2 Bio, Consultant for: Sanofi, AB2 Bio, AbbVie, Pfizer, BMS, MSD, Roche, Novartis, D. Nordstrom: None declared, O. FitzGerald Grant/research support from: Pfizer, Abbvie, BMS, Novartis, UCB, Janssen, Celgene and Lilly, M. Hernández Miguel: None declared, M. Santos: None declared, Z. Rotar: None declared, H. Mann: None declared,
F. Iannone Consultant for: AbbVie, BMS, Eli Lilly, Janssen, MSD, Novartis, Pfizer, Roche, UCB, M. J. Nissen: None declared, E. Hauge: None declared, J. Gomez-Reino: None declared, F. Díaz-González: None declared, M. Tomsic: None declared, K. Pavelka: None declared, F. O'Shea: None declared, C. Sullivan: None declared, M. van de Sande: None declared, I. E. van der Horst-Bruinsma: None declared, G. J. Macfarlane Grant/research support from: Pfizer, AbbVie and UCB, G. T. Jones Grant/research support from: AbbVie, Pfizer, UCB, B. Gudbjørnsson: None declared, T. K. Kvien Consultant for: AbbVie, Biogen, BMS, Boehringer Ingelheim, Celltrion, Eli Lilly, Epirus, Janssen, Merck-Serono, MSD, Mundipharma, Novartis, Oktal, Orion Pharma, Hospira/Pfizer, Roche, Sandoz and UCB

DOI: 10.1136/annrheumdis-2017-eular.3659

\section{FRI0451 SEX DIFFERENCES IN DISEASE ACTIVITY ACCORDING TO COMPOSITE INDICES IN SPONDYLOARTHRITIS: A SYSTEMATIC REVIEW AND META-ANALYSIS}

M. Blasco-Blasco ${ }^{1}$, I. Castrejón ${ }^{2}$, V. Jovaní ${ }^{3}$, E. Eliseo ${ }^{4}$, M. Ruiz-Cantero ${ }^{1,5}$. ${ }^{1}$ Public Health, University of Alicante, Alicante, Spain; ${ }^{2}$ Rheumatology, Rush University Medical Center, Chicago, United States; ${ }^{3}$ Rheumatology, Alicante University General Hospital; ${ }^{4}$ Rheumatology, Miguel Hernández University; ${ }^{5}$ Ciberesp, Alicante, Spain

Background: The Bath Ankylosing Spondylitis (AS) Disease Activity Index (BASDAI), an index of only patient-self-report measures, and AS Disease Activity Score $\left(\right.$ ASDAS) ${ }^{1}$, which adds patient global estimate and laboratory tests to BASDAl elements are widely used in Spondyloarthritis (SpA). Both indices are specifically designed to evaluate disease activity AS patients. Some studies have shown worse BASDAI in women, but sex-related differences by ASDAS remain unclear ${ }^{2,3}$.

Objectives: To analyze reports of sex-stratified disease activity measures -BASDAI and ASDAS- in patients with SpA.

Methods: Data sources included PubMed (1950 to December 2016), Embase, Web Of Science, and manual searches of references lists. We included observational studies and randomized trials comparing disease activity scores, specifically BASDAI and ASDAS, between men and women with SpA. Studies quality was determined in line with the STROBE statement for observational studies and CONSORT statement for RCT, considering $<50 \%$ positive items as low quality. Randomized effects were performed to report the mean difference ( $95 \%$ confidence interval) by gender, and heterogeneity was measured via $\mathrm{I}^{2}$ statistic in order to check the results robustness.

Results: From 672 identified studies 18 cross-sectional studies, 3 cohort, 2 case-control studies, and 1 RTC reported sex-stratified BASDAI and ASDAS. ASDAS was evaluated in 3.758 patients ( $36.5 \%$ women) in 9 studies, and BASDAI included 12,329 patients (34.3\% women) in 24 studies. In a metanalysis of mean difference BASDAI including 19 studies the mean difference was $0.56(95 \% \mathrm{Cl}$ : $0.47,0.66)$ and $\mathrm{I}^{2}=43 \%$, indicating a significantly higher disease activity in women (Figure). In a metanalysis of 7 studies ASDAS the mean difference was 0.06 $(95 \% \mathrm{Cl}:-0.04,0.16)$ and $\mathrm{I}^{2}=41 \%$, not showing statistically significant differences.

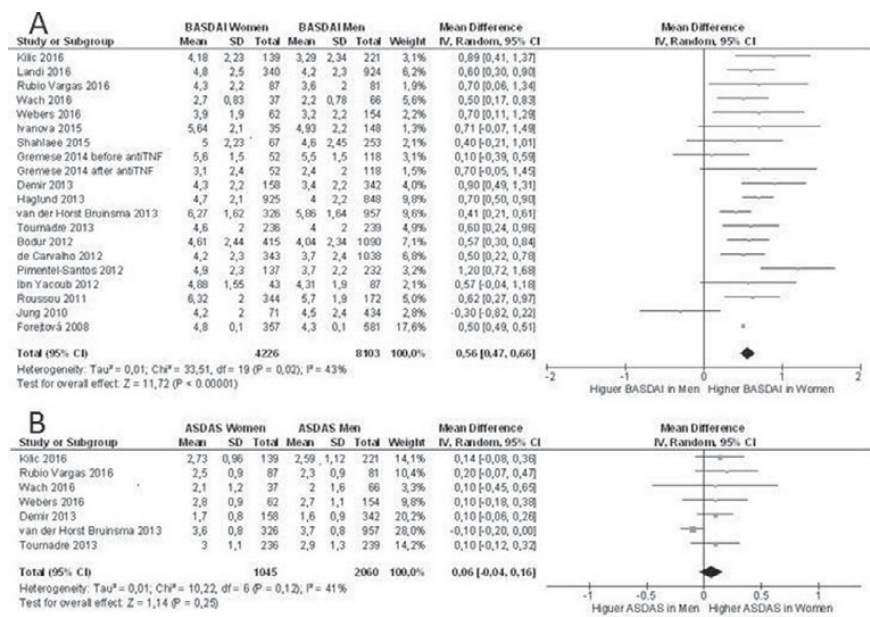

Figure. (A) Mean difference to BASDAI in men vs woman. (B) Mean difference to ASDAS in men vs woman

Conclusions: We identified relevant sex differences in disease activity according to BASDAI with higher disease activity in women, but not according to ASDAS. In $\mathrm{SpA}$, women present more peripheral arthritis and higher pain, which may influence the BASDAI score, mainly based on patient-self-report measures. It is important to recognize these differences that may influence management decisions based on disease activity measures.

References:

[1] van der Heijde D et al. Ann Rheum Dis 2009;68:1811-18.

[2] van der Horst-Bruinsma IE et al. Ann Rheum Dis 2013;72:1221-1224. 